See discussions, stats, and author profiles for this publication at:

http://www.researchgate.net/publication/233474013

\title{
Cournot and Stackelberg equilibrium in mixed duopoly models
}

ARTICLE in OPTIMIZATION · JULY 2010

Impact Factor: $0.77 \cdot$ DOI: 10.1080/02331930802434773

CITATIONS

2
DOWNLOADS

17
VIEWS

369

3 AUTHORS, INCLUDING:

Vitaliy Kalashnikov

Autonomous University of Nuevo ...

17 PUBLICATIONS 64 CITATIONS

SEE PROFILE

Vitaly Kalashnikov

Autonomous University of Nuevo ...

61 PUBLICATIONS 218 CITATIONS

SEE PROFILE 
This article was downloaded by: [Vyacheslav Kalashnikov]

On: 24 July 2013, At: 03: 15

Publisher: Taylor \& Francis

Informa Ltd Registered in England and Wales Registered Number: 1072954 Registered

office: Mortimer House, 37-41 Mortimer Street, London W1T 3J H, UK

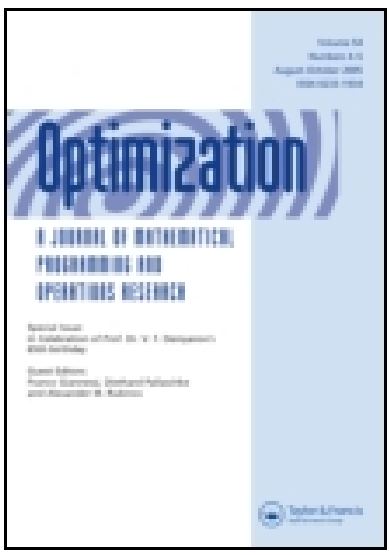

\title{
Optimization: A J ournal of Mathematical Programming and Operations Research
}

Publication details, including instructions for authors and subscription information: http:// www.tandfonline.com/loi/gopt20

\section{Cournot and Stackelberg equilibrium in mixed duopoly models}

\author{
Vyacheslav Kalashnikov ${ }^{a}$, Alvaro Eduardo Cordero ${ }^{a} \&$ Vitaly \\ Kalashnikov ${ }^{\text {b }}$ \\ a Tecnológico de Monterrey (ITESM), Campus Monterrey, Mexico \\ ${ }^{b}$ Department of Civil Engineering and Architecture (FICA), \\ Durango State University (UJ ED), Gómez Palacio, Mexico \\ Published online: 22 Oct 2008.
}

To cite this article: Vyacheslav Kalashnikov, Alvaro Eduardo Cordero \& Vitaly Kalashnikov (2010) Cournot and Stackelberg equilibrium in mixed duopoly models, Optimization:

A J ournal of Mathematical Programming and Operations Research, 59:5, 689-706, DOI:

$10.1080 / 02331930802434773$

To link to this article: http:// dx.doi.org/ 10.1080/ 02331930802434773

\section{PLEASE SCROLL DOWN FOR ARTICLE}

Taylor \& Francis makes every effort to ensure the accuracy of all the information (the "Content") contained in the publications on our platform. However, Taylor \& Francis, our agents, and our licensors make no representations or warranties whatsoever as to the accuracy, completeness, or suitability for any purpose of the Content. Any opinions and views expressed in this publication are the opinions and views of the authors, and are not the views of or endorsed by Taylor \& Francis. The accuracy of the Content should not be relied upon and should be independently verified with primary sources of information. Taylor and Francis shall not be liable for any losses, actions, claims, proceedings, demands, costs, expenses, damages, and other liabilities whatsoever or howsoever caused arising directly or indirectly in connection with, in relation to or arising out of the use of the Content.

This article may be used for research, teaching, and private study purposes. Any substantial or systematic reproduction, redistribution, reselling, loan, sub-licensing, systematic supply, or distribution in any form to anyone is expressly forbidden. Terms \& 

and-conditions 


\title{
Cournot and Stackelberg equilibrium in mixed duopoly models
}

\author{
Vyacheslav Kalashnikov $^{\mathrm{a} *}$, Alvaro Eduardo Cordero ${ }^{\mathrm{a}}$ and Vitaly Kalashnikov ${ }^{\mathrm{b}}$ \\ ${ }^{a}$ Tecnológico de Monterrey (ITESM), Campus Monterrey, Mexico; \\ ${ }^{b}$ Department of Civil Engineering and Architecture (FICA), Durango State University (UJED), \\ Gómez Palacio, Mexico
}

(Received 12 July 2007; final version received 7 May 2008)

\begin{abstract}
We investigate Cournot and Stackelberg mixed duopoly models where a stateowned public firm maximizing domestic social surplus, and a foreign firm searching to maximize its own profit, compete. First, we establish the existence and uniqueness results for the Cournot scheme, and propose the agents' classification as strong or weak according to the agent's optimal reaction function properties at the Cournot equilibrium. Then we examine a desirable role (either leader or follower) of both firms in the Stackelberg schemes and compare the profits and domestic social surplus and the production volumes at each type of Stackelberg equilibrium.
\end{abstract}

Keywords: mixed duopoly; Cournot equilibrium; Stackelberg equilibrium

AMS Subject Classifications: 91B52; 91B54; 91B60; 91B68

\section{Introduction}

Examinations of mixed oligopolies, in which social surplus-maximizing public firms compete against profit-maximizing private firms, have become increasingly popular in recent years. For pioneering works on mixed oligopolies, see [1,2,4,11]. Excellent surveys can be found in $[3,12,14]$.

The interest in mixed oligopolies is high because of their importance in the economies of Europe (Germany, England and others), Canada and Japan (see [10] for analysis of 'herd behaviour' by private firms in many branches of the economy in Japan). There are examples of mixed oligopolies in United States such as the packaging and overnight delivery industries. Mixed oligopolies are also common in the East European and former Soviet Union transitional economies, in which competition among public and private firms existed or still exists in many industries such as banking, house loan, airlines, telecommunication, natural gas, electric power, hospital, health care, railways and others.

*Corresponding author. Email: kalash@itesm.mx 
These situations have been investigated in different ways. Many works analysed Cournot and Stackelberg models with the role of each firm assigned exogenously. However, it is reasonable to assume that each firm decides what actions to take, and when to take them.

DeFraja and Delbono [3] are pioneers in these investigations. They showed that in simultaneous-move games, privatization of the public firm may improve welfare. In [9] it is shown that under certain conditions, the partial privatization of the public firm improves welfare. Pal [13] found that the public firm can be follower, but he assumed that private firms are domestic.

In the paper by Matsumura [8], the author investigates mixed duopoly and analyses a desirable role (either leader or follower) of the public firm, when the inverse demand function is concave. Under these conditions, Matsumura found that the role of the public firm should be that of the leader (however, the author makes assumptions about the concavity of domestic social surplus and profit function with respect to the volumes of the domestic public firm and private foreign firm, respectively). Matsumura also establishes that domestic social surplus in a mixed duopoly is greater than in a monopolistic market.

In this article, we also examine the desirable roles of both the foreign private agent and the domestic public firm. In contrast to [8], here we do not require the inverse demand function to be concave. Hence the model describes more general situations, and the role of firms in the observable delay game could be either leader or follower.

An extended abstract of this work was published in the Proceedings of the 2nd International Conference on Innovative Computing, Information and Control (ICICIC'2007), Kumamoto, Japan, September 05-07, 2007 (cf [7]).

The article is organized as follows: In Section 2, we describe the model and establish existence and uniqueness theorems for the Cournot equilibrium. After analysing the agents' optimal response functions at the Cournot equilibrium, we define the concept of a strong firm and a weak firm. Section 3 deals with the game where the domestic public firm is the leader and the private foreign firm is the follower. Section 4 considers the game where the domestic public firm is the follower and the private foreign firm is the leader. The domestic public firm may have two different types of optimal reaction at the Cournot equilibrium, and as a consequence this firm could be weak or strong. Finally, in Section 5, we make comparisons between the domestic social surplus quantities and the private firm's profits at various Stackelberg and Cournot equilibrium states, and we examine the observable delay game when the private firm is strong and when it is weak.

Due to the volume restrictions, we omit certain lengthy proofs, which will appear elsewhere.

\section{Model specification}

Consider two firms producing a homogeneous product. Let $G$ represent the total output, and $p(G)$ denote an inverse demand function, i.e. the price of a unit of the product. The goods produced by the two firms are sold on the domestic market. Let $q_{i}, i=1,2$, denote the output of firm $i$. Let $c_{i}\left(q_{i}\right)$ stand for the production cost by firm $i$. As $G$ is the total output, one has

$$
G=q_{1}+q_{2} .
$$


Firm 1 is a foreign private firm, which maximizes its own profits, and firm 2 is a domestic public firm that maximizes domestic social surplus. Domestic social surplus $S$ is the sum of consumer surplus and profits of firm 2, and is given by

$$
S\left(G, q_{2}\right)=\int_{0}^{G} p(x) \mathrm{d} x-\left[p(G) q_{1}+c_{2}\left(q_{2}\right)\right] ;
$$

here of course, $q_{1}=G-q_{2}$.

The profit of firm 1 is given by:

$$
\Pi\left(G, q_{1}\right)=p(G) q_{1}-c_{1}\left(q_{1}\right) .
$$

We also want to solve an observable delay game. This game consists of three stages. At the first stage, each firm $i, i=1,2$ independently chooses $e_{i} \in\{2,3\}, i=1,2$, where $e_{i}$ indicates when to produce the output $q_{i}$. Namely, $e_{i}=2$ implies that firm $i$ produces at the second stage, and $e_{i}=3$ means that firm $i$ produces at the third stage. In the end of the first stage, each firm select its $e_{i} \in(2,3)$. At the second stage, each firm $i$ choosing $e_{i}=2$ assigns its output $q_{i}$. At the third stage, each firm $i$ choosing $e_{i}=3$ selects its output $q_{i}$. In the end of the game, the market opens and each firm $i$ sells its output. This is a complete information game, i.e. each firm knows the rival's choice at the first stage.

We accept the following assumptions concerning the inverse demand function and cost functions:

A1. Let $p(G) \geq 0$ be a twice continuously differentiable function defined over $G>0$, with $p^{\prime}(G)<0$ and $p(G) G$ being a strictly concave function. Moreover, we assume that

$$
p^{\prime}(G)-p^{\prime \prime}(G) G<0 \text { for } G>0 .
$$

A2. We assume that the cost functions $c_{i}\left(q_{i}\right), i=1,2$, are twice continuously differentiable, non-decreasing and convex, with non-negative values defined over $q_{i} \geq 0$ (i.e. $\left.c_{i}\left(q_{i}\right) \geq 0\right)$.

A3. For $i=1$, there exists an $H_{1}>0$, such that:

$$
c_{1}^{\prime}\left(H_{1}\right)=p\left(H_{1}\right)
$$

whereas for $i=2$, there exists an $H_{2}>0$, such that:

$$
p\left(H_{2}\right)-H_{1}\left(1+\frac{H_{1}}{H_{2}}\right) p^{\prime}\left(H_{2}\right)=c_{2}^{\prime}\left(H_{2}\right) .
$$

\section{A4. Principle of potential participation}

For $i=1$, there exist $G_{0}>0$ and $q_{1}^{0}>0$ such that $G<G_{0}$ implies that for $q_{1}<q_{1}^{0}$ the following (strict) inequality holds:

$$
p(G)+p^{\prime}(G) G-c_{1}^{\prime}\left(q_{1}\right)>0 .
$$

Remark 2.1 Assumptions A1 and A2 are quite natural and common for works analysing equilibrium in the homogeneous good markets. Examples of functions that satisfy $\mathbf{A} \mathbf{1}$ are: $p(G)=A G^{-\gamma}$ with $A>0$ and $0<\gamma<1$, among others. Inequality (2.4) is evidently true if the inverse demand function $p(G)$ is convex and decreasing. However, it also allows the 
function $p(G)$ to be concave, but not 'too concave', that is, not with a 'too negative' second derivative $p^{\prime \prime}(G)$.

Remark 2.2 Assumption $\mathbf{A 3}$ is also common enough to avoid unlimited production incentives for both agents. The principle of potential participation given in $\mathbf{A 4}$ excludes the possibility of the trivial (zero) equilibrium.

Remark 2.3 Relationships $p(G) \geq 0$ and $p^{\prime}(G)<0$ for all $G>0$ from assumption A1 imply that

$$
\lim _{G \rightarrow \infty} p^{\prime}(G)=0
$$

Hence, the relationship

$$
p\left(H_{2}\right)-H_{1}\left(1+\frac{H_{1}}{H_{2}}\right) p^{\prime}\left(H_{2}\right)=c_{2}^{\prime}\left(H_{2}\right)
$$

of assumption $\mathbf{A 3}$ yields that there exists an $H_{3}>0$ such that

$$
p(G)-H_{1}\left(1+\frac{H_{1}}{H_{2}}\right) p^{\prime}(G)-c_{2}^{\prime}\left(q_{2}\right)<0 \quad \text { for all } G \geq q_{2}>H_{3} .
$$

To make it possible to define an equilibrium with only first-order optimality conditions, we first have to verify that the profit and/or domestic social surplus functions are concave over their domains. We do that by establishing the following auxiliary results given without proof that will appear elsewhere.

Lemma 2.1 Under assumptions $\mathbf{A 1}$ and $\mathbf{A 2}$, firm 1's profit function $\Pi\left(G, q_{1}\right)$ is concave with respect to $q_{1}$.

Lemma 2.2 Under assumptions $\mathbf{A 1}$ and $\mathbf{A 2}$, the domestic social surplus function $S\left(G, q_{2}\right)$ is concave with respect to $q_{2}$.

Remark 2.4 It is easy to see that if one assumes the cost functions $c_{i}, i=1,2$, to be strictly convex, then both Lemmas 2.1 and 2.2 guarantee the strict concavity of the respective objective functions $\Pi$ and $S$.

Now we are in a position to define different kinds of equilibrium states and compare the equilibrium volumes for various scenarios. First, we consider the classical Cournot equilibrium, i.e. a vector $Z=\left(G, q_{1}, q_{2}\right) \in R_{+}^{3}$, such that:

$$
\begin{gathered}
G=\sum_{i=1}^{2} q_{i}, \\
q_{1} \geq 0, \varphi_{1} \equiv c_{1}^{\prime}\left(q_{1}\right)-q_{1} p^{\prime}(G)-p(G) \geq 0, \quad q_{1} \varphi_{1}=0 ; \\
q_{2} \geq 0, \varphi_{2} \equiv c_{2}^{\prime}\left(q_{2}\right)+\left(G-q_{2}\right) p^{\prime}(G)-p(G) \geq 0, \quad q_{2} \varphi_{2}=0 .
\end{gathered}
$$

Problem (2.7)-(2.9) is a standard complementarity problem. Therefore, to establish the existence of solutions to the latter, we can use powerful theoretical tools developed in the book by Isac, Bulavsky and Kalashnikov [5]. 
Theorem 2.3 (Existence Theorem) Let assumptions A1-A4 be valid. Then the Cournot equilibrium problem (2.7)-(2.9) has a (non-trivial) solution.

Proof The existence of solutions to problems (2.7)-(2.9) follows from the next result. This Cournot equilibrium problem is a standard complementarity problem and can be rewritten in the following form: Find a vector $x \in R^{2}$ such that:

$$
x \geq 0, F(x) \geq 0 \text { and } x^{T} F(x)=0 ;
$$

here

$$
x=\left(q_{1}, q_{2}\right)^{T}, F_{1}(x)=-\frac{\partial}{\partial q_{1}} \Pi\left(G, q_{1}\right) \quad \text { and } \quad F_{2}(x)=-\frac{\partial}{\partial q_{2}} S\left(G, q_{2}\right) .
$$

As it follows from assumption A1, the mapping $F: R_{+}^{2} \rightarrow R^{2}$ is continuous over the nonnegative quadrant $R_{+}^{2}$. We may use the following theorem to establish the existence of solutions.

TheOrem 6.8 [5] Consider a continuous mapping $F: R_{+}^{n} \rightarrow R^{n}$ and a non-empty bounded subset $C \subset R_{+}^{n}$ such that for every $x \in R_{+}^{n}$ and $x \notin C$, the inequality

$$
x_{i} F_{i}(x)>0
$$

is valid for at least one of the indices $i=1, \ldots, n$. Then problem (2.10) has a solution, and all the solutions belong to $C$.

Coming back to the proof of Theorem 2.3, select a (non-empty) subset

$$
C=\left\{x \in R^{2} \mid 0 \leq q_{1} \leq H_{1}, 0 \leq q_{2} \leq H_{3}\right\},
$$

with $\mathrm{H}_{3}$ defined in Remark 2.3 (see inequality (2.6)). Now we prove that inequality (2.12) holds for at least one index at any point $x$ outside the subset $C$. Consider an arbitrary $x \notin C$, that is, at least one of the following conditions is valid:

(i) $q_{1}>H_{1}$. In this case, according to assumptions A1-A4, we get the inequality

$$
p(G)-f_{1}^{\prime}\left(q_{1}\right)<0 \text { for all } G \geq q_{1}>H_{1} .
$$

Now recall that

$$
F_{1}(x)=c_{1}^{\prime}\left(q_{1}\right)-q_{1} p^{\prime}(G)-p(G),
$$

which, together with (2.14), immediately implies that $F_{1}(x)>0$, hence

$$
x_{1} F_{1}(x)=q_{1} F_{1}(x)>0 \text { for any } q_{1}>H_{1} .
$$

Inequality (2.15) implies formula (2.12) in case (i).

(ii) Assume that $0 \leq q_{1} \leq H_{1}$, but $q_{2}>H_{3}$. In that case, by assumptions A1-A4, the following inequality holds:

$$
p(G)-H_{1}\left(1+\frac{H_{1}}{H_{2}}\right) p^{\prime}(G)-c_{1}^{\prime}\left(q_{2}\right)<0 \quad \text { for } G \geq q_{2}>H_{3} .
$$

Let us examine the component $F_{2}(x)$ :

$$
F_{2}(x)=c_{1}^{\prime}\left(q_{2}\right)+q_{1} p^{\prime}(G)-p(G)
$$


as $0 \leq q_{1} \leq H_{1}, q_{2}>H_{3}, G=q_{1}+q_{2}$ and $p^{\prime}(G)<0$, we deduce from (2.16) and (2.17) that:

$$
\begin{aligned}
F_{2}(x) & =c_{1}^{\prime}\left(q_{2}\right)+q_{1} p^{\prime}(G)-p(G) \\
& \geq c_{1}^{\prime}\left(q_{2}\right)+H_{1} p^{\prime}(G)-p(G) \\
& \geq c_{1}^{\prime}\left(q_{2}\right)+H_{1}\left(1+\frac{H_{1}}{H_{2}}\right) p^{\prime}(G)-p(G)>0 .
\end{aligned}
$$

Thus, the last inequality implies $x_{2} F_{2}(x)=q_{2} F_{2}(x)>0$, that is, (2.12) is valid for any $x \notin C$ in case (ii), too. Therefore, to complete the proof of Theorem 2.3, it suffices to apply Theorem 6.8.

Now we turn to examining uniqueness properties of the Cournot equilibrium defined by (2.7)-(2.9). First we engage in determining the uniqueness of a non-monopolistic equilibrium volume. To do that, we need to involve an extra assumption concerning the inverse demand function $p$.

Definition 2.1 Let $Z=\left[G, q_{1}, q_{2}\right]$ be an equilibrium, i.e. a solution of the Cournot problem (2.7)-(2.9). We say that this equilibrium is non-monopolistic if $q_{i}<G, i=1,2$.

A5. Assume that the product $p^{\prime}(G) G$ is a non-decreasing function over $G>0$.

Remark 2.5 Assumption A5 implies that the inverse demand function's decrease rate is not too high (in other words, the negative slope $p^{\prime}(G)$ is 'not too negative'). Moreover, it is clear that assumption $\mathbf{A 5}$ is equivalent to the condition

$$
p^{\prime}(G)+p^{\prime \prime}(G) G \geq 0, \quad \text { for } G>0,
$$

which, together with assumption A1, implies the convexity of the inverse demand function $p$.

Theorem 2.4 (Theorem of Uniqueness) Under assumptions A1, $\mathbf{A 2}$ and A5, the cleared market quantity $G$ is the same at each non-monopolistic equilibrium.

Remark 2.6 When the equilibrium is non-monopolistic, then according to Theorem 2.4, the cleared market volume $G$ is determined uniquely. However, in some cases both monopolistic and non-monopolistic equilibrium states with distinct volumes can occur. For instance, that may happen if the cost functions $c_{i}$ and the product $p(G) G$ are piece-wise linear functions.

We finish this section with a result guaranteeing the uniqueness of not only the equilibrium cleared market volume $G$ but also the complete equilibrium state $Z=\left(G, q_{1}, q_{2}\right)$.

COROllary 2.5 Under assumptions A1-A5, the equilibrium state $Z$ exists uniquely.

Proof First, under assumptions A1-A4, there are equilibrium states. Moreover, as assumption A4 implies, no agent can have zero production volume, hence all the equilibrium states are non-monopolistic. Therefore, Theorem 2.4 implies that the equilibrium cleared market volume $G$ is unique. Now suppose that for the same volume $G$, there exist two distinct pairs $\left[q_{1}^{(1)}, q_{2}^{(1)}\right]$ and $\left[q_{1}^{(2)}, q_{2}^{(2)}\right]$ satisfying the balance equality

$$
G=\sum_{i=1}^{2} q_{i}^{(1)}=\sum_{i=1}^{2} q_{i}^{(2)},
$$


and the respective pair of complementarity relationships (2.8) and (2.9). Without affecting generality assume that

$$
0<q_{1}^{(1)}<q_{1}^{(2)}
$$

Hence, assumption $\mathbf{A 2}$ implies that

$$
-c_{1}^{\prime}\left(q_{1}^{(1)}\right) \geq-c_{1}^{\prime}\left(q_{1}^{(2)}\right)
$$

Moreover, as it follows from (2.8), $\varphi_{1}\left(q_{1}^{(1)}\right)=\varphi_{1}\left(q_{1}^{(2)}\right)=0 \quad$ (because both $q_{1}^{(1)}>0$ and $q_{1}^{(2)}>0$ ), and making use of (2.19), (2.20) and the negativity of $p^{\prime}(G)$, one has the following chain of relationships:

$$
\begin{aligned}
0 & =\varphi_{1}\left(q_{1}^{(2)}\right) \equiv p(G)+q_{1}^{(2)} p^{\prime}(G)-c_{1}^{\prime}\left(q_{1}^{(2)}\right) \\
& <p(G)+q_{1}^{(1)} p^{\prime}(G)-c_{1}^{\prime}\left(q_{1}^{(1)}\right) \equiv \varphi_{1}\left(q_{1}^{(1)}\right)=0,
\end{aligned}
$$

which implies an impossible inequality $0<0$. This contradiction completes the proof of the uniqueness of the equilibrium contribution by the foreign agent $q_{1}$. Finally, the balance equality (2.18) guarantees the uniqueness of the domestic firm's equilibrium production volume $q_{2}$ as well.

\section{Stackelberg model with leadership of domestic (public) firm}

First, in this section, we examine the game where firm 2 (the public one) is the leader. Firm 2 chooses its output volume $q_{2}$, and firm 1 (the private one) chooses $q_{1}$ after having observed $q_{2}$, so as to maximize its net profit:

$$
\Pi\left(G, q_{1}\right)=p(G) q_{1}-c_{1}\left(q_{1}\right) .
$$

Let $q_{1}=q_{1}\left(q_{2}\right) \geq 0$ be the (optimal) reaction function of firm 1 ; that is, the value that satisfies the equality

$$
\varphi_{1}\left(q_{1}\left(q_{2}\right)\right) \equiv \frac{\partial}{\partial q_{1}} \Pi\left(G, q_{1}\left(q_{2}\right)\right) \leq 0 \quad \text { and } \quad \varphi_{1}\left(q_{1}\left(q_{2}\right)\right) \cdot q_{1}\left(q_{2}\right)=0 .
$$

By convexity of the cost function $c_{1}$ and by assumption $\mathbf{A} \mathbf{3}$, this reaction function is well defined. Indeed, if $p(G)>c_{1}^{\prime}(0)$ then one can obtain $q_{1}\left(q_{2}\right)$ by solving the first-order optimality condition:

$$
\frac{\partial \Pi\left(G, q_{1}\right)}{\partial q_{1}}=p(G)+p^{\prime}(G) q_{1}-c_{1}^{\prime}\left(q_{1}\right)=0
$$

otherwise, i.e. if $p(G) \leq c_{1}^{\prime}(0)$, then $q_{1}\left(q_{2}\right)=0$. In other words,

$$
q_{1}\left(q_{2}\right)=0 \quad \text { for all } q_{2} \geq \tilde{q}_{2}=p^{-1}\left[f_{1}^{\prime}(0)\right] .
$$

Remark 3.1 Notice that the value $\tilde{q}_{2}>0$ defined by (3.4) exists uniquely due to assumptions $\mathbf{A 1}-\mathbf{A 4}$, if $c_{1}^{\prime}(0)>0$. Otherwise, i.e. if $c_{1}^{\prime}(0)=0$, then $\tilde{q}_{2}=+\infty$, or in other words, $q_{1}\left(q_{2}\right)>0$ for all $q_{2}>0$. 
On the one hand, if the value $\tilde{q}_{2}>0$ is finite, then

$$
q_{1}^{\prime}\left(q_{2}\right)=0 \quad \text { for all } q_{2}>\tilde{q}_{2} \text { and } q_{1}^{\prime}\left(\tilde{q}_{2}+0\right)=0 .
$$

On the other hand, when $q_{2}<\tilde{q}_{2}$ then the derivative $q_{1}^{\prime}\left(q_{2}\right)$ can be found making use of the second-order equation obtained by differentiating the left-hand side of Equation (3.3) with respect to $q_{2}$ :

$$
p^{\prime}(G)+p^{\prime \prime}(G) q_{1}\left(q_{2}\right)+\left[2 p^{\prime}(G)+p^{\prime \prime}(G) q_{1}\left(q_{2}\right)-c_{1}^{\prime \prime}\left(q_{1}\right)\right] q_{1}^{\prime}(G)=0,
$$

whence

$$
q_{1}^{\prime}\left(q_{2}\right)=\frac{p^{\prime}(G)+p^{\prime \prime}(G) q_{1}}{c_{1}^{\prime \prime}\left(q_{1}\right)-2 p^{\prime}(G)-p^{\prime \prime}(G) q_{1}} .
$$

The denominator in (3.6) is always positive: indeed, $c_{1}^{\prime \prime}\left(q_{1}\right) \geq 0$ by assumption $\mathbf{A 2}$, and $2 p^{\prime}(G)+p^{\prime \prime}(G) G<0$ by the strict concavity of the function $p(G) G(\mathbf{A 1})$. Now if $p^{\prime \prime}(G) \leq 0$, then $2 p^{\prime}(G)+p^{\prime \prime}(G) q_{1}<0$, hence the denominator in (3.6) is strictly positive. Finally, if $p^{\prime \prime}(G)>0$, then one has the chain of inequalities

$$
2 p^{\prime}(G)+p^{\prime \prime}(G) q_{1} \leq 2 p^{\prime}(G)+p^{\prime \prime}(G) G<0,
$$

which again yields the strict positivity of the denominator in (3.6). Therefore, (3.6) implies

$$
q_{1}^{\prime}\left(q_{2}\right) \begin{cases}\leq 0 & \text { if } p^{\prime}(G)+p^{\prime \prime}(G) q_{1} \leq 0 \\ >0 & \text { otherwise. }\end{cases}
$$

Now we introduce the following classification of agents, according to their optimal reaction function's properties at the Cournot equilibrium. Such a classification was considered first in [6] and can be also found in the book by Isac, Bulavsky and Kalashnikov [5]. To do that, we denote the (unique) solution of the Cournot game (2.7)-(2.9) total volume by $G^{C}$.

Definition 3.1 A firm is called strong if the derivate of its reaction function is nonnegative at the Cournot equilibrium cleared market volume $G^{C}$, that is, if $q_{i}^{\prime}\left(G^{C}-q_{i}\right) \geq 0$. Respectively, a firm is called weak if its reaction function's derivative is negative at the Cournot equilibrium, that is, if $q_{i}^{\prime}\left(G^{C}-q_{i}\right)<0$.

Remark 3.2 Definition 3.1 is based upon the potential reaction of firm $i$ when the latter assumes that the rival firm $j$ increases its output. If the reaction of firm $i$ is not to decrease its output, firm $i$ is a strong firm. But if firm $i$ decreases its output, firm $i$ is a weak firm. For example, (3.7) implies that, under assumptions A1-A4, if the inverse demand function $p$ is concave then the private firm is always weak.

Now we realize a comparative analysis for various strategies of the firms. We are going to compare the volume of the Cournot equilibrium $G^{C}$ with those of Stackelberg equilibrium states when the domestic public firm is the leader $G^{F, L}$, and when the private firm is the leader $G^{L, F}$. Also, we compare domestic social surplus and the profits of the private firm at these various equilibrium states.

\section{Lemma 3.1 Under assumptions A1-A4,}

$$
q_{1}^{\prime}\left(q_{2}\right)>-1 \text { for all } q_{2} \neq \tilde{q}_{2} .
$$


Moreover, if the value $\tilde{q}_{2}>0$ is finite then $q_{1}^{\prime}\left(\tilde{q}_{2}-0\right)<0$ and $q_{1}^{\prime}\left(\tilde{q}_{2}+0\right)=0$.

Proof Rewrite (3.6) as follows:

$$
q_{1}^{\prime}\left(q_{2}\right)=\frac{p^{\prime}(G)+p^{\prime \prime}(G) q_{1}}{c_{1}^{\prime \prime}\left(q_{1}\right)-p^{\prime}(G)-\left[p^{\prime}(G)+p^{\prime \prime}(G) q_{1}\right]} .
$$

Now if $q_{1}^{\prime}\left(q_{2}\right) \geq 0$, then (3.8) trivially holds. Otherwise, if $q_{1}^{\prime}\left(q_{2}\right)<0$, i.e. if $p^{\prime}(G)+p^{\prime \prime}(G) q_{1}<0$, then (3.9) clearly implies (3.8) due to the inequality

$$
c_{1}^{\prime \prime}\left(q_{1}\right)-p^{\prime}(G)>0 .
$$

Finally, as $q_{1}\left(q_{2}\right)=0$ for $q_{2} \geq \tilde{q}_{2}$, one evidently has

$$
q_{1}^{\prime}\left(\tilde{q}_{2}-0\right)=\frac{p^{\prime}\left(\tilde{q}_{2}\right)}{c_{1}^{\prime \prime}(0)-2 p^{\prime}\left(\tilde{q}_{2}\right)}<0 \quad \text { and } \quad q_{1}^{\prime}\left(\tilde{q}_{2}+0\right)=0,
$$

which, together with relationship (3.8), completes the proof.

Now firm 2 (domestic producer) chooses $q_{2} \equiv Q \geq 0$ so as to maximize

$$
S_{2}(Q) \equiv S(G(Q), Q)=\int_{0}^{G(Q)} p(q) \mathrm{d} q-p(G(Q)) q_{1}(Q)-c_{2}(Q),
$$

where

$$
G(Q)=q_{1}(Q)+Q
$$

First, we examine some basic properties of the domestic social surplus function $S_{2}(Q)$. Definition (3.13) implies that if the value $\tilde{q}_{2}>0$ is finite, then

$$
G(Q) \begin{cases}\geq Q & \text { if } Q \leq \tilde{q}_{2} \\ =Q & \text { if } Q>\tilde{q}_{2}\end{cases}
$$

Hence, the function $G=G(Q)$ is differentiable at every point $Q \neq \tilde{q}_{2}$, with

$$
G^{\prime}(Q)=q_{1}^{\prime}(Q)+1, \quad \text { when } Q \neq \tilde{q}_{2} .
$$

Lemma 3.1 guarantees that

$$
G^{\prime}(Q)>0, \quad \text { for all } Q \neq \tilde{q}_{2} \text {. }
$$

At the point $Q=\tilde{q}_{2}$, the function $G(Q)$ may have only one-side derivatives:

$$
\begin{aligned}
0<G^{\prime}\left(\tilde{q}_{2}-0\right) & =q_{1}^{\prime}\left(\tilde{q}_{2}-0\right)+1<1, \\
G^{\prime}\left(\tilde{q}_{2}+0\right) & =q_{1}^{\prime}\left(\tilde{q}_{2}+0\right)+1=1 .
\end{aligned}
$$

Furthermore, since $q_{1}^{\prime}(Q)=0$ for $Q>\tilde{q}_{2}$, (3.17) implies that

$$
G^{\prime}(Q)=1 \quad \text { for all } Q>\tilde{q}_{2}
$$


Now differentiating the domestic social surplus function (3.12) with respect to $Q$ and using the relationship (3.15), one gets for $Q \neq \tilde{q}_{2}$

$$
\begin{aligned}
S_{2}^{\prime}(Q) \equiv & \frac{\mathrm{d}}{\mathrm{d} Q} S(G(Q), Q)=p(G(Q)) G^{\prime}(Q)-p^{\prime}(G(Q)) G^{\prime}(Q) q_{1}(Q) \\
& -p(G(Q)) q_{1}^{\prime}(Q)-c_{2}^{\prime}(Q) \\
= & p(G(Q))\left[G^{\prime}(Q)-q_{1}^{\prime}(Q)\right]-p^{\prime}(G(Q)) G^{\prime}(Q) q_{1}(Q)-c_{2}^{\prime}(Q) \\
= & p(G(Q))-p^{\prime}(G(Q)) G^{\prime}(Q) q_{1}(Q)-c_{2}^{\prime}(Q) .
\end{aligned}
$$

In a similar manner we obtain the formulas for the one-side derivatives of the domestic social surplus at the point $Q=\tilde{q}_{2}$ when it is finite:

$$
S_{2}^{\prime}\left(\tilde{q}_{2} \pm 0\right)=p\left(\tilde{q}_{2}\right)-c_{2}^{\prime}\left(\tilde{q}_{2}\right)
$$

As the one-side derivatives are equal, we can conclude that domestic social surplus is differentiable at the point $Q=\tilde{q}_{2}$ as well, with

$$
S_{2}^{\prime}\left(\tilde{q}_{2}\right)=p\left(\tilde{q}_{2}\right)-c_{2}^{\prime}\left(\tilde{q}_{2}\right) .
$$

Now we are in a position to recall a mathematically rigorous definition of the Stackelberg equilibrium state with the domestic leader and foreign follower.

Definition 3.2 A Stackelberg equilibrium (with the domestic firm as a leader and the foreign firm as a follower) is the vector $Z=\left(G^{F, L}, q_{1}^{F}\left(Q^{L}\right), Q^{L}\right) \in R_{+}^{3}$ such that

$$
\begin{gathered}
G^{F, L}=q_{1}^{F}\left(Q^{L}\right)+Q^{L}, \\
Q^{L} \in \operatorname{Arg} \max \left\{S_{1}(Q) \mid Q \geq 0\right\}, \\
q_{1}^{F}\left(Q^{L}\right)=\arg \max \left\{\Pi\left(G^{F, L}, q_{1}\right) \mid q_{1} \geq 0\right\} .
\end{gathered}
$$

Next we establish relationships to compare the production volumes of the firms at the Stackelberg equilibrium state (3.22)-(3.24) to those at the Cournot equilibrium defined by the complementarity problem (2.7)-(2.9). Besides, it is interesting to compare the values $Q^{C}$ and $Q^{L}$ to the domestic firm's optimum output volume $Q^{P}$ at the perfect competition equilibrium, that is, when the domestic producer ignores the price variation and solves the following complementarity problem: Find a $Q \geq 0$ such that

$$
\beta_{2}(Q) \equiv c_{2}^{\prime}(Q)-p(G(Q)) \geq 0 \quad \text { and } \quad \beta_{2}(Q) Q=0 .
$$

The proof is omitted due to the paper volume restrictions.

TheOREM 3.2 Under assumptions A1-A4, the following estimates hold:

$$
0<Q^{P} \leq \min \left\{Q^{C}, Q^{L}, H_{3}\right\}
$$

here $\mathrm{H}_{3}$ is the parameter from Remark 2.3.

Remark 3.3 When the value $\tilde{q}_{2}>0$ is finite, it is easy to see that if

$$
c_{2}^{\prime}\left(\tilde{q}_{2}\right) \geq p\left(\tilde{q}_{2}\right)=c_{1}^{\prime}(0),
$$


then

$$
S_{2}^{\prime}(Q)=p(Q)-c_{2}^{\prime}(Q)<0 \quad \text { for all } Q>\tilde{q}_{2},
$$

which means that

$$
Q^{L} \leq \tilde{q}_{2}
$$

Relationships (3.27)-(3.29) also imply that

$$
Q^{C} \leq \tilde{q}_{2} .
$$

Therefore, due to $\mathbf{A 3}$, one can deduce that

$$
\max \left\{Q^{C}, Q^{L}\right\} \leq \max \left\{\tilde{q}_{2}, H_{2}\right\} .
$$

Inequality (3.30) allows one to conclude that if $\tilde{q}_{2} \leq H_{2}$ then (3.26) may be rewritten as follows:

$$
0<Q^{P} \leq \min \left\{Q^{C}, Q^{L}\right\} \leq \max \left\{Q^{C}, Q^{L}\right\} \leq H_{2}\left(\leq H_{3}\right) .
$$

Note that the estimates obtained in Theorem 2.2 and Remark 3.3 involve the expressions $\min \left\{Q^{C}, Q^{L}\right\}$ and $\max \left\{Q^{C}, Q^{L}\right\}$, because assumptions A1-A4 in general do not imply the (strict) concavity of the leader's (domestic social surplus) function $S_{2}(Q)$ over all $Q \geq 0$. Now we introduce an additional assumption which allows one to establish this concavity of the domestic social surplus function and hence deduce more exact global comparative static results making use of some local information only.

A6. Assume that the foreign firm's cost function is linear:

$$
c_{1}\left(q_{1}\right)=c_{1} q_{1}, \quad \text { for all } q_{1} \geq 0,
$$

where $c_{1}>0$ is a constant, and the inverse demand function has the following property: the ratio

$$
\frac{p^{\prime \prime}(G)}{p^{\prime}(G)}
$$

is a differentiable function of $G>0$, and the following estimate holds:

$$
\frac{\mathrm{d}}{\mathrm{d} G}\left(\frac{p^{\prime \prime}(G)}{p^{\prime}(G)}\right) \geq-\frac{1}{G} \cdot \frac{p^{\prime \prime}(G)}{p^{\prime}(G)} .
$$

Remark 3.4 Examples of functions that satisfy (3.34) are: $p(G)=A G^{-\gamma}$ with $A>0$ and $0<\gamma \leq 1$, among others.

TheOREM 3.3 Under assumptions A1-A4 and A6, and with the leadership of the domestic supplier, the domestic social surplus function $S_{2}(Q)$ is strictly concave over $Q \geq 0$.

Being too long, we omit the proof of the above result, to be published elsewhere. Now we can obtain the complete comparative static classification for the Cournot and Stackelberg equilibrium states under assumptions A1-A4 and A6. 
THeOREm 3.4 Under assumptions A1-A4 and A6, and with the leadership of the domestic supplier, the following global estimates based upon the local information are true:

(i) If $G^{\prime}\left(Q^{C}-0\right) \leq 1$ and $G^{\prime}\left(Q^{C}+0\right)=1$, then $Q^{L}=Q^{C}$, hence $G\left(Q^{L}\right)=G\left(Q^{C}\right)$. This case can occur only at the point $Q^{L}=Q^{C}=\tilde{q}_{2}$.

(ii) If $G^{\prime}\left(Q^{C}-0\right)>1$, then $Q^{L}>Q^{C}$, hence $G\left(Q^{L}\right)>G\left(Q^{C}\right)$.

(iii) If $G^{\prime}\left(Q^{C}+0\right)<1$, then $Q^{L}<Q^{C}$, hence $G\left(Q^{L}\right)<G\left(Q^{C}\right)$.

Proof Due to relationships (3.5), (3.11) and (3.15), case (i) indeed may happen only at the point $Q=\tilde{q}_{2}$ with $q_{1}=q_{1}\left(\tilde{q}_{2}\right)=0$. Then formulas (2.9), (3.19)-(3.21) give us $S_{2}^{\prime}\left(\tilde{q}_{2}\right)=0$, which implies (due to the strict concavity of the function $S_{2}$ obtained in Theorem 3.3) that $Q^{L}=\tilde{q}_{2}$. On the other hand, it is easy to see that in this case, $Z=\left(\tilde{q}_{2}, 0, \tilde{q}_{2}\right)$ satisfies conditions (2.7)-(2.9), thus yielding that $Q^{C}=\tilde{q}_{2}$.

In case (ii), which corresponds to a strong foreign firm with $q_{1}^{\prime}\left(Q^{C}\right)>0$, formula (3.19) yields $S_{2}^{\prime}\left(Q^{C}\right)>0$, hence by Theorem 2.3 we deduce that the maximum domestic surplus occurs beyond the Cournot volume, i.e.

$$
Q^{L}>Q^{C}, \text { hence } G\left(Q^{L}\right)>G\left(Q^{C}\right) .
$$

At last, case (iii) reflecting the weakness of the foreign participant with $q_{1}^{\prime}\left(Q^{C}\right)<0$ implies by (3.19) that $S_{2}^{\prime}\left(Q^{C}\right)<0$. Again Theorem 2.3 makes it possible to conclude that the domestic leader's optimum production volume with $S_{2}^{\prime}\left(Q^{L}\right)=0$ must be lower than the Cournot volume, that is,

$$
Q^{L}<Q^{C}, \text { hence } G\left(Q^{L}\right)<G\left(Q^{C}\right) .
$$

The theorem has been proved completely.

Remark 3.5 Case (i) in Theorem 3.4 occurs if and only if

$$
S_{2}^{\prime}\left(\tilde{q}_{2}\right)=0 \text {, i.e. } p\left(\tilde{q}_{2}\right)=c_{2}^{\prime}\left(\tilde{q}_{2}\right) \text {. }
$$

However, since $\tilde{q}_{2}=p^{-1}\left[c_{1}^{\prime}(0)\right]=p^{-1}\left(c_{1}\right)$, (3.37) means that

$$
c_{1}^{\prime}(0)=c_{1}=c_{2}^{\prime}\left(\tilde{q}_{2}\right) .
$$

Hence, under assumptions A1-A4 and A6, equality (3.38) can be solved for the parameter value $\tilde{q}_{2}$ as follows:

$$
\tilde{q}_{2}=p^{-1}\left(c_{1}\right)=\left(c_{2}^{\prime}\right)^{-1}\left(c_{1}\right)
$$

Remark 3.6 Cases (ii) and (iii) in Theorem 3.4 allow the following interpretation. Although the total domestic surplus is always higher if the domestic producer is a leader, because

$$
S_{2}\left(Q^{L}\right) \geq S_{2}\left(Q^{C}\right)
$$

by definitions (3.22)-(3.24), it is interesting to note that the total market cleared volume in the Stackelberg scenario grows compared to that in the Cournot equilibrium only if the foreign producer is a strong firm. Indeed, case (ii) with $G^{\prime}\left(Q^{C}\right)>1$ means that

$$
q_{1}^{\prime}\left(Q^{C}\right)>0 .
$$


On the contrary, if $q_{1}^{\prime}\left(Q^{C}\right)<0$, that is, when the foreign participant is weak, one comes to case (iii), with $Q^{L}<Q^{C}$, hence $G\left(Q^{L}\right)<G\left(Q^{C}\right)$ and thus

$$
p\left(G\left(Q^{L}\right)\right)>p\left(G\left(Q^{C}\right)\right) .
$$

Therefore, for an individual consumer concerned with the good's retail price, it would be better if the domestic producer as a leader of the market were accompanied by a strong foreign competitor as a follower.

\section{Stackelberg model with leadership of foreign (private) firm}

Now consider the game where firm 1 (foreign private firm) is a leader. Firm 1 chooses $q_{1}$ and firm 2 (domestic or public supplier) chooses $q_{2}$ after having observed $q_{1}$, so as to maximize domestic social surplus:

$$
S\left(G, q_{2}\right)=\int_{0}^{G} p(q) \mathrm{d} q-q_{1} p(G)-c_{2}\left(q_{2}\right) ;
$$

here

$$
G=q_{1}+q_{2} .
$$

Let $q_{2}\left(q_{1}\right)$ be the reaction function of firm 2 ; that is, the quantity that satisfies the optimality condition below:

$$
q_{2}\left(q_{1}\right)=\underset{q_{2} \geq 0, G=q_{1}+q_{2}}{\arg \max } S\left(G, q_{2}\right) .
$$

This reaction function is well defined due to convexity of the cost function $c_{2}$ and assumption A3. Moreover, assumptions A2 and A4 imply that if $q_{1}=0$ then the reaction value of firm 2 solving the equation

$$
p\left(q_{2}\right)=c_{2}^{\prime}\left(q_{2}\right)
$$

is always positive but not exceeding the upper bound $H_{2}$ from assumption A3. Otherwise, if $q_{1}>0$, then the reaction value of firm 2 solves the complementarity problem (2.9):

$$
q_{2} \geq 0, \varphi_{2} \equiv c_{2}^{\prime}\left(q_{2}\right)+q_{1} p^{\prime}(G)-p(G) \geq 0, \quad q_{2} \varphi_{2}=0
$$

and again, it is strictly positive and not exceeding $H_{2}$. This means that $q_{2}=q_{2}\left(q_{1}\right)>0$ is the unique solution of the equation

$$
p(G)-q_{1} p^{\prime}(G)-c_{2}^{\prime}\left(q_{2}\right)=0 .
$$

Now taking into account (4.2) and differentiating the obtained equation with respect to $q_{1}$ one gets:

$$
p^{\prime}(G)\left[1+q_{2}^{\prime}\left(q_{1}\right)\right]-p^{\prime}(G)-q_{1} p^{\prime \prime}(G)\left[1+q_{2}^{\prime}\left(q_{1}\right)\right]-c_{2}^{\prime \prime}\left(q_{2}\left(q_{1}\right)\right) q_{2}^{\prime}\left(q_{1}\right)=0,
$$

whence

$$
q_{2}^{\prime}\left(q_{1}\right)=\frac{q_{1} p^{\prime \prime}(G)}{p^{\prime}(G)-q_{1} p^{\prime \prime}(G)-c_{2}^{\prime \prime}\left(q_{2}\left(q_{1}\right)\right)} .
$$


The denominator in ratio (4.7) is always negative. Indeed, $-c_{2}^{\prime \prime}\left(q_{2}\left(q_{1}\right)\right) \leq 0$ due to assumption A2; next, if $p^{\prime \prime}(G) \geq 0$, then $p^{\prime}(G)-q_{1} p^{\prime \prime}(G)<0$ by assumption $\mathbf{A 1}$ as $p^{\prime}(G)<0$; finally, if $p^{\prime \prime}(G)<0$, one yields the chain of inequalities

$$
p^{\prime}(G)-q_{1} p^{\prime \prime}(G) \leq p^{\prime}(G)-p^{\prime \prime}(G) G<0
$$

by (2.4) in assumption A1. Therefore, we conclude that

$$
q_{2}^{\prime}\left(q_{1}\right)\left\{\begin{array}{ll}
\leq 0 & \text { if } p^{\prime \prime}(G) \geq 0 ; \\
>0 & \text { if } p^{\prime \prime}(G)<0 ;
\end{array} \quad \text { for all } G>0 .\right.
$$

Remark 4.1 Formula (4.8) has an interesting economic interpretation: the domestic producer (firm 2) is always weak if the inverse demand function is convex, and is always strong if the latter is concave.

Now firm 1 (foreign producer) selects a $q_{1} \equiv Q \geq 0$ so as to maximize its profit function

$$
\Pi_{1}(Q) \equiv \Pi(G(Q), Q)=p(G(Q)) Q-c_{1}(Q),
$$

where

$$
G(Q)=Q+q_{2}(Q) .
$$

By differentiating (4.10) with respect to $Q$ one gets

$$
G^{\prime}(Q)=1+q_{2}^{\prime}(Q) .
$$

Now differentiating the foreign firm's profit (4.9) by $Q$ one yields

$$
\Pi_{1}^{\prime}(Q)=p(G(Q))+p^{\prime}(G(Q)) G^{\prime}(Q) Q-c_{1}^{\prime}(Q) .
$$

Definition 4.1 A Stackelberg equilibrium (with the foreign firm as a leader and the domestic firm as a follower) is the vector $Z=\left(G^{L, F}, Q_{1}^{L}, q_{2}^{F}\left(Q_{1}^{L}\right)\right) \in R_{+}^{3}$ such that

$$
\begin{gathered}
G^{L, F}=Q_{1}^{L}+q_{2}^{F}\left(Q_{1}^{L}\right), \\
Q_{1}^{L} \in \operatorname{Arg} \max \left\{\Pi_{1}\left(Q_{1}\right) \mid Q_{1} \geq 0\right\}, \\
q_{2}^{F}\left(Q^{L}\right)=\arg \max \left\{S\left(G^{L, F}, q_{2}\right) \mid q_{2} \geq 0\right\} .
\end{gathered}
$$

In what follows we establish relationships which allow one to compare the production volumes of the cleared market at the Stackelberg equilibrium (4.13)-(4.15) to those at the Cournot equilibrium defined with the complementarity problem (2.7)-(2.9). Besides, it is instructive to compare the values $Q_{1}^{C}$ and $Q_{1}^{L}$ to the foreign firm's optimum output $Q_{1}^{P}$ in the perfect competition equilibrium, that is, when the foreign (private) producer ignores variations in price and solves the following complementarity problem: Find a $Q_{1} \geq 0$ such that

$$
\beta_{1}\left(Q_{1}\right) \equiv c_{1}^{\prime}\left(Q_{1}\right)-p\left(G\left(Q_{1}\right)\right) \geq 0 \quad \text { and } \quad \beta_{1}\left(Q_{1}\right) Q_{1}=0 .
$$


Remark 4.2 It is easy to see that the solution $Q_{1}^{P}$ of problem (4.16) always exists and does not exceed the parameter value $H_{1}$ from assumption A3. Assumption A4 also guarantees that $Q_{1}^{P}$ has a positive value:

$$
0<Q_{1}^{P} \leq H_{1}
$$

First of all, we note that $Q_{1}^{L}$ solves the following complementarity problem: Find a $Q_{1} \geq 0$ such that

$$
\mu_{1}\left(Q_{1}\right) \equiv c_{1}^{\prime}\left(Q_{1}\right)-p^{\prime}\left(G\left(Q_{1}\right)\right) G^{\prime}\left(Q_{1}\right) Q_{1}-p\left(G\left(Q_{1}\right)\right) \geq 0 \quad \text { and } \quad \mu_{1}\left(Q_{1}\right) Q_{1}=0,
$$

with

$$
G\left(Q_{1}\right)=Q_{1}+q_{2}\left(Q_{1}\right),
$$

while $Q_{1}^{C}$ is a solution to the complementarity problem (2.8): Find a $Q_{1} \geq 0$ such that

$$
\varphi_{1}\left(Q_{1}\right) \equiv c_{1}^{\prime}\left(Q_{1}\right)-p^{\prime}\left(G\left(Q_{1}\right)\right) Q_{1}-p\left(G\left(Q_{1}\right)\right) \geq 0, \quad \text { and } \quad \varphi_{1}\left(Q_{1}\right) Q_{1}=0,
$$

where

$$
G\left(Q_{1}\right)=Q_{1}+q_{2}^{C}=Q_{1}+Q^{C} .
$$

Finally, recall that $Q_{1}^{F}$ solves the following complementarity problem: Find a $Q_{1} \geq 0$ such that

$$
\kappa_{1}\left(Q_{1}\right) \equiv c_{1}^{\prime}\left(Q_{1}\right)-p^{\prime}\left(G\left(Q_{1}\right)\right) Q_{1}-p\left(G\left(Q_{1}\right)\right) \geq 0 \quad \text { and } \quad \kappa_{1}\left(Q_{1}\right) Q_{1}=0,
$$

with

$$
G\left(Q_{1}\right)=Q_{1}+Q_{2}^{L} .
$$

THEOREM 4.1 Under assumptions A1-A4, with a strictly convex cost function $c_{1}$ and a convex inverse demand function $p$, the following relationships are valid:

$$
0 \leq Q_{1}^{C} \leq Q_{1}^{L} \leq Q_{1}^{P} \leq H_{1}
$$

Otherwise, if the function $p$ is concave, we have the inequalities below:

$$
0 \leq Q_{1}^{L} \leq Q_{1}^{C} \leq Q_{1}^{P} \leq H_{1} .
$$

As the proof of the above theorem is quite lengthy, we omit it to publish later elsewhere.

Remark 4.3 If we assume that $G^{\prime}\left(Q_{1}\right)>0$ (which, e.g., is guaranteed if $p$ is concave, $\mathrm{cf}$ (4.8) and (4.11), but not only in this case) we can make interesting conclusions concerning the cleared market volume in different scenarios. On the one hand, when $p^{\prime \prime} \geq 0$, inequalities (4.24) imply the relationships

$$
G^{C}=G\left(Q_{1}^{C}\right) \leq G\left(Q_{1}^{L}\right)=G^{L, F} \leq G\left(Q_{1}^{P}\right) .
$$

These relationships mean that when the domestic producer is weak, the leadership of the private firm is better for the individual consumer than the Cournot competition between 
the private and public producers, as the former may result in a lower retail price of the good on the market.

On the other hand, if the inverse demand function is concave, i.e. $p^{\prime \prime} \leq 0$, then inequalities (4.25), together with $G^{\prime}\left(Q_{1}\right)>0$, yield

$$
G^{L, F}=G\left(Q_{1}^{L}\right) \leq G\left(Q_{1}^{C}\right)=G^{C} \leq G\left(Q_{1}^{P}\right),
$$

which clearly indicate that if the domestic producer is strong, then the leadership of the private firm may lower the total market volume against the Cournot equilibrium and hence raise the good's retail price on the market.

\section{Solution of observable delay game}

Now denote the domestic social surplus optimal values and the foreign firm's profits at the various forms of equilibrium as follows:

$$
\begin{array}{lll}
S^{L} \equiv S_{2}\left(Q_{2}^{L}\right), & S^{C} \equiv S\left(G^{C}, q_{2}^{C}\right) & \text { and } S^{F} \equiv S\left(G^{L, F}, q_{2}^{F}\right) \\
\Pi^{L} \equiv \Pi_{1}\left(Q_{1}^{L}\right), & \Pi^{C} \equiv \Pi\left(G^{C}, q_{1}^{C}\right) & \text { and } \Pi^{F} \equiv \Pi\left(G^{F, L}, q_{1}^{F}\right) .
\end{array}
$$

To find possible equilibrium states in the observable delay game described in the beginning of Section 2, we need to compare the values $S^{L}, S^{C}$ and $S^{F}$, and the values $\Pi^{L}$, $\Pi^{C}$ and $\Pi^{F}$ as defined in (5.1). Due to the definition of the Stackelberg equilibrium, it is clear that

$$
S^{L} \geq S^{C} \text { and } \Pi^{L} \geq \Pi^{C} .
$$

As to the comparison between values of $S^{C}$ and $S^{F}$, we establish the following result (the proof will be presented elsewhere).

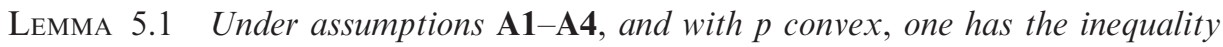

$$
S^{F} \geq S^{C} .
$$

On the other hand, if $p$ is concave, we come to the inequality

$$
S^{F} \leq S^{C} .
$$

The next result compares the values of $\Pi^{C}$ and $\Pi^{F}$. Again, the proof is omitted due to the volume restrictions.

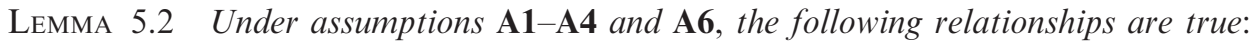

(i) If $G^{\prime}\left(Q_{2}^{C}-0\right) \leq 1$ and $G^{\prime}\left(Q_{2}^{C}+0\right)=1$, then $\Pi^{F}=\Pi^{C}$. This case can occur only when $Q_{2}^{L}=Q_{2}^{C}=\tilde{G}_{1}$.

(ii) If $G^{\prime}\left(Q_{2}^{C}-0\right)>1$, then $\Pi^{F}<\Pi^{C}$.

(iii) If $G^{\prime}\left(Q_{2}^{C}+0\right)<1$, then $\Pi^{F}>\Pi^{C}$.

Now summing up the results obtained in Theorems 3.4 and 4.1, and Lemmas 5.1 and 5.2, we may analyse all possible equilibrium states in the observable delay game cited in the beginning of the article. Proof of the following theorem will be published elsewhere. 
THEOREM 5.3 Under assumptions A1-A4 and A6, and with a convex inverse demand function $p$ (and hence with a weak public firm), the following results hold:

(i) If $G^{\prime}\left(Q_{2}^{C}-0\right)>1$, then there is only one Nash equilibrium in the observable delay game: $e^{*}=(2,3)$, which means that the (strong) private firm is a leader and the public firm is a follower.

(ii) Otherwise, if $G^{\prime}\left(Q_{2}^{C}+0\right)<1$, then there are two Nash equilibria in the observable delay game: the same $e_{1}^{*}=(2,3)$ as in case (i), and the second one $e_{2}^{*}=(3,2)$; the latter meaning that the public firm is a leader and the private firm is a follower.

On the other hand, if the inverse demand function $p$ is concave, and hence we have a strong public firm and a weak private firm, only one case is possible:

(iii) $A s G^{\prime}\left(Q_{2}^{C}+0\right)<1$, then there is only one Nash equilibrium in the observable delay game: $e^{*}=(3,2)$, which means that the public firm is a leader and the private firm is a follower.

\section{Conclusion}

In the presented analysis, we investigated three different types of equilibria in the duopoly with a private (foreign) agent aiming at maximization of its own profit, and a domestic firm maximizing domestic social surplus. After having obtained the existence and uniqueness results for the Cournot equilibrium in the above-described model, we examined two versions of Stackelberg game, with the private firm as a leader and domestic one as a follower, and vice versa.

In order to compare the equilibrium volumes in various scenarios we introduce the concepts of a weak and a strong firm, in dependence on the sign of the agent's optimal reaction function's derivative at the Cournot equilibrium. With such a characteristic, it turns out that if the inverse demand function is convex, then the domestic producer is always weak, and vice versa: if the inverse demand function is concave, then the domestic agent is always strong.

For the Stackelberg equilibrium with the domestic producer as a leader, we obtain that the production volume by the leader (and hence, the total cleared market volume) is higher than that in the Cournot equilibrium, if the private firm (the follower) is strong. Otherwise, if the private agent is weak, then the total cleared market volume is lower with the domestic producer as a leader than that would be in the Cournot equilibrium.

Next, if the foreign (private) firm is a leader, then the relations between the leader's (and hence, the total) production volumes directly depend upon the strength of the domestic producer as a follower: if the domestic producer is weak, then the leader's production volume is higher than that would be in the Cournot equilibrium; otherwise, when the domestic firm is strong, the private leader's output (and hence the total cleared market volume) is lower than that in the Cournot equilibrium.

Comparing the corresponding values of the agents' objective functions (the profit function for the private firm, and domestic social surplus for the public firm), we find that in the observable delay game with the two participants, the number of Nash equilibrium states depends upon their relative efficiency. Namely, if the private firm is strong and the domestic producer is weak, then only one Nash equilibrium exists in the observable delay game, and that is the Stackelberg equilibrium with the private firm as a leader. Next, if both the foreign (private) and the domestic (public) agents are weak, then two 
Nash equilibrium states occur: one is the same as just mentioned, and another one with the roles interchanged: the domestic agent being a leader and the foreign firm being a follower. Finally, when the domestic producer is strong and the foreign one is weak, again only one Nash equilibrium in the observable delay game exists, and it is the Stackelberg equilibrium with the domestic (public) producer as a leader and the foreign (private) firm as a follower.

\section{Acknowledgements}

This research was supported by the Mexico National Council on Science and Technology (CONACyT) within the project SEP-2004-C01-45786; the work of the first and the second author was also supported with the Department of Research in Logistics (Cátedra de Investigación) CAT025 of the Tecnológico de Monterrey; the work of the first author was supported by the Russian Humanitary Science Foundation (RGNF) grant no. 08-02-00271; the work of the third author was also supported by Cuerpo Académico of the Department of Civil Engineering and Architecture (FICA) of the University of Durango (UJED). The authors also express their profound gratitude to an anonymous referee for the valuable comments and remarks that have helped to improve the manuscript.

\section{References}

[1] D. Bös, Public Enterprise Economics, North-Holland, Amsterdam, 1986.

[2] — Privatization: A Theoretical Treatment, Clarendon Press, Oxford, 1991.

[3] G. De Fraja and F. Delbono, Game theoretic models of mixed oligopoly, J. Econ. Surveys 4 (1990), pp. 1-17.

[4] R.G. Harris and E.G. Wiens, Government enterprise: an instrument for the internal regulation of industry, Can. J. Econ. 13 (1980), pp. 125-132.

[5] G. Isac, V.A. Bulavsky, and V.V. Kalashnikov, Complementarity, Equilibrium, Efficiency and Economics, Kluwer Academic Publishers, Dordrecht/Boston/London, 2002, p. 468.

[6] V.V. Kalashnikov, Complementarity Problems and Oligopoly Models. Dr Sci. Diss., Central Economics and Mathematics Institute (CEMI) of the Russian Academy of Sciences, Moscow. 1995, p. 253 (in Russian).

[7] V.V. Kalashnikov, E. Cordero, and V.V. Kalashnikov Jr, Stackelberg equilibrium in a mixed duopoly, in Proceedings of the 2nd International Conference on Innovative Computing, Information and Control (ICICIC'2007), September 05-07, 2007, Kumamoto, Japan, p. 4.

[8] T. Matsumura, Stackelberg mixed duopoly with a foreign competitor, Bull. Econ. Res. 55 (2003), pp. $275-287$.

[9] T. Matsumura and N. Matsushima, Endogenous cost differentials between public and private enterprises: A mixed duopoly approach. Economica, London School of Economics and Political Science, 74, (284) (2004), pp. 671-688.

[10] N. Matsushima and T. Matsumura, Mixed oligopoly and spatial agglomeration. Can. J. Econ., Can. Econ. Assoc. 36, (1) (2003), pp. 62-87.

[11] W. Merril and N. Schneider, Government firms in oligopoly industries: a short-run analysis, Q. J. Econ. 80 (1966), pp. 400-412.

[12] L. Nett, Mixed oligopoly with homogeneous goods, Ann. Public Coop. Econ. 64 (1993), pp. 367-393.

[13] D. Pal, Endogenous trimming in a mixed oligopoly, Econ. Lett. 61 (1998), pp. 181-185.

[14] J. Vickers and G. Yarrow, Privatization - An Economic Analysis, MIT Press, Cambridge, 1998. 